\title{
Role of PET/CT in Differentiating Synchronous Second Primary Lung Masses from Lung Metastases
}

\author{
RANIA S. ABOUKHADRAH, M.D. and GHADA S. SHERBASH, M.D.
}

The Department of Radiology, Faculty of Medicine, Tanta University

\begin{abstract}
Background: In case of multiple pulmonary and extrapulmonary lesions, it is difficult to determine if the lung mass was primary lesion or metastasis from a distant organ, even in multiple pulmonary lesions. it is difficult to determine sit of primary one.
\end{abstract}

Aim of Study: We retrospectively measure the $\mathrm{SUV}_{\max }$ and $\Delta_{\text {SUVmax }}$ in pulmonary and extrapulmonary lesions and identify if there is a cutoff value of logically proved synchronous second primary and metastatic lesions.

Patients and Methods: 65 patients (50 male and 15 female with age ranged from 35 to 70 years) who had multiple pulmonary and extrapulmonary lesions were evaluated by PET/CT, all patients were evaluated by oncology physicians, patients were selected after histopathological evaluation, patients with lung metastasis taken as a control group. $\mathrm{SUV}_{\max }$ and $\Delta_{\text {SUVmax }}$ were measured in both groups.

Results: A significant $(\Delta \mathrm{SUV}){ }_{\max }$ difference between both included groups: Metastatic lung cancers and second primary lung tumours with a cutoff value of $35 \%$ while no significant $\Delta S U V_{\max }$ between the studied cases in the same groups, as below this level approved for metastatic lesion and above this cutoff values consistent with the synchronous second primary tumour, this help in better staging and management of lung cancer.

Conclusion: PET CT is considered as a functional noninvasive technique, we recommended that all patients with multiple pulmonary and extrapulmonary lesions to add this investigation, before taking the decision of management, it can differentiate between multiple primaries and metastatic lesion depending upon the FDG activity.

Key Words: Second primary lung masses - Lung metastases - PET/CT $-\triangle S U V_{\max }$

\section{Introduction}

INCIDENCE of mortality from lung cancer increasing rapidly due to increase commerciality of cigarette smoking, lung cancer is now a popular

Correspondence to: Dr. Rania Sobhy Aboukhadrah, The Department of Radiology, Faculty of Medicine, Tanta University disease that needs early diagnosis and understands to improving its staging and early management that improve the overall survival [1,2].

Primary lung cancer send metastasis to different organs in the body mainly to lungs, brain, breast colon, and genitourinary tract. Synchronous primary lung cancer means two primaries in the same time or within at least 6 months after discovering the first one, one primary in the lung and the other one may be in the lung or any other distant organ. The incidence of a simultaneous second primary lung cancer is about $1-8 \%$ from all cases of lung cancer [3].

The presence of two or more lesions within the lung or outside is a big dilemma about where is the primary. Two primaries are a common developing problem with increasing its detection rate due to advance in early detection techniques as CT and PET/CT and advance in cancer therapy. Differentiation between multiple lesions as synchronous or metastatic will influence the strategy of treatment and determined the survival rate. In case of multiple primaries surgical removal was the best choice for treatment while, metastatic lesions chemo and radiotherapy were the choices for treatment and the survival rate of multiple primaries is better than that of metastatic lesions [4].

Tumours had the same clonal origin often behave in a similar way and have the same histological features, Dijkman B.G., et al., hypothesized that the SUVs of clonally related masses (i.e. metastases) would be closely resembling than those of

\footnotetext{
Abbreviations:

PET : Positron Emission Tomography.

CT : Computerized Tomography.

SUV : Standardized Uptake Value.

FDG : Fluoro-Deoxy-Glucose.

SCLC : Squamous Cell Lung Cancer.
} 
tumours with a different clonal origin. Consequently, they hypothesized that the SUVs of metastases nearing the SUV of the primary tumour they originate from and that the SUVs of two primary tumours differ markedly.

Imaging of lung cancer and its metastasis using conventional CT is still the main imaging modality to detect the morphological criteria of the masses including: Site, size, density, outlines, lymph nodes and metastasis to different organs but it lacked proper delineation of actual outlines of mass from nearby consolidation or collapse, differentiation between the different pathological and metastatic processes which will improve TMN staging, detection of the most active site for a biopsy which improves the outcome of surgical operation if indicated, and actual detection of residual or recurrent mass from post-operative sequel [5,6].

Newly functioning imaging tools used for accurate TMN staging as whole-body diffusionweighted-MRI (WB diffusion WI-MRI) and PET/ $\mathrm{CT}$. Wb diffusion WI carried the advantage of no ionizing radiation exposure and less coast than $\mathrm{PET} / \mathrm{CT}$ [7].

PET/CT played an important role in diagnosis, staging and follow-up of patients with lung masses. It anticipated the metastasis even small lesions moreover both metastases, as well as synchronous primary tumours, can be visualized.

Lung cancer divided into small-cell and nonsmall cell, the small-cell includes the adenocarcinoma, large cell carcinoma and squamous cell carcinoma, and adenocarcinoma considered to metastasis early and appeared as a peripheral mass [8].

Few trials tried to investigate the role of SUV. $\max$ in differentiating between lung metastases and synchronous second primary lung tumours PET/CT had shown encouraging results as F-18 FDG PET imaging provided metabolic information, based on the increased glucose metabolism in malignant lesions. The CT component on integrated PET/CT had a limited role for correcting the attenuation and for anatomic localization in the past. The metabolic parameters on PET and the HU on the integrated PET/CT scan can be used together for the identification of nature of these multiple lesions. There is no consensus on the accurate diagnostic criteria for differentiation of lung metastases and synchronous second primary lung tumours with using these two parameters [9].

Our study investigated the role of PET/CT in the diagnosis of the pulmonary and extrapulmonary lesions in case of multiple lesions trying to detect the second primary and differentiating it from metastasis and study the role of SUVmax of both primary and metastasis this will help to improve early staging and management and overall survival rates.

\section{Patients and Methods}

\section{Patients population:}

Our retrospective study included 65 patients (50 males and 15 females with age ranged from 35 to 70 year, mean age was 52.4) with multiple pulmonary and extrapulmonary lesions (18 had second primary lung masses and 47 had lung metastases, total lesions $=150$ ), all patients referred from Oncology Department after histopathological analysis of lesions to PET/CT Unit of Tanta University hospitals either for staging or post-operative to assess the operative bed and re-staging, this study took three years of duration started from April 2016 to March 2019, this study was Approved by Ethical Committee of Tanta University Hospital as tabulated in Fig. (1).

Patients referred from Oncology Department after histopathological analysis of lesions and then referred to PET/CT unit for staging or post-operative for re-staging from April 2016 to March 2019 (n=65)

Second primary group $(n=18)$ :

- Patient with primary lung tumor and any other second primary (pathologically proved).

- Not surgically treated or with pervious cancer-related therapy.

- Synchronous mass, occurring <6 months, proven by biopsy.

- Not with insufficient biopsies.

- Not with multiple masses but with no definite. Histopathological diagnosis.

- Not pregnant female.

- Not with random blood glucose level of $>200 \mathrm{mg} / \mathrm{dl}$.
Metastatic group as a control group $(n=47)$ :

- Patient with metastatic lung cancer (stag III or IV) (pathologically proved).

- Patient with extrapulmonary primary and metastasis to lung.

- Not with insufficient biopsies.

- Not with multiple masses but with no definite histopathological diagnosis.

- Not pregnant female.

- Not with random blood glucose level of $>200 \mathrm{mg} / \mathrm{dl}$. 
Inclusion criteria: Patients with multiple pulmonary and extrapulmonary lesions that underwent histopathological evaluation for both lesions (in case of multiple pulmonary lesions biopsy taken from the largest nodule which had malignant morphological criteria on conventional CT).

Exclusion criteria: Patients with previous cancer-related therapy, patient with multiple masses, but with no definite histopathological diagnosis. Pregnant female, patients with a random blood glucose level of $>200 \mathrm{mg} / \mathrm{dl}$ and patients with insufficient biopsies as shown in flowchart Fig. (1).

All patients referred for PET/CT unit for staging or post-operative assessment and detection of the hidden site for metastasis.

\section{Methods:}

A- A full history taking as regard to patient age, weight, height, sex, complaint, history of diabetes, smoking and smoking index.

B- MDCT was done for all patients as a first imaging modality, which gives us an idea about the anatomical and morphological data and detects infiltration and extension of the mass to nearby structures and detects distant metastasis. In case of multiple lesions, we depend on morphological criteria as a nodule with speculation, irregular outlines and nearby traction and fibrosis were favours of primary cancer. Presence of multiple lesions with round outlines and sharp border favours for metastatic lesions.

C- Histopathological analysis was done for both original and distant metastatic lesions.

\section{D- Fused PET/CT:}

Preparation: Combined PET/CT was done for all patients on a 16-multidetector scanner (Siemens). Patients should be fasted for at least 4 hours with the pre-scanning measuring of random blood glucose level, patients with high blood glucose level referred to internal medicine department to correct the glucose level, all metallic objects should be removed, patients wear a specific gown and IV cannula was inserted, patients asked to limit their movements and avoid stressful condition to avoid physiological uptake.

Patient's weight and height should be measured to calculate the dose of FDG, the patients put in a suitable warm environment to avoid brown fat stimulation, patients also instructed to ingest diet high-fat, low in carbohydrate and protein $24 \mathrm{~h}$ before the examination. $10 \mathrm{mCi}(1 \mathrm{ml} / 10 \mathrm{~kg}) 18-\mathrm{F}-$ FDG was injected manually 45-60min before starting the examination in the previously inserted IV cannula. This period is known as the uptake phase which is the time for the 18-FDG to be adequately bio distributed to the patients' cells. Patients were asked after isotope administration to rest in a quiet isolated room.

Non enhanced CT scanning was performed from the base of the skull with arm extended above the head, parameters of CT were 125-kv. Pitch of 1.5 , reconstructed slice thickness of $4 \mathrm{~mm}$ and 16 slice acquisition, average duration about $20 \mathrm{sec}$. the attenuation correction of CT data done with suspended breath-hold this followed by CT scan with contrast with the same previous CT parameters, contrast material was administrated by injector by a rate of $2 \mathrm{ml} / \mathrm{sec}$, PET emission scan was acquired with a spatial resolution of $4.8 \mathrm{~mm}$ and with slice thickening of $3 \mathrm{~mm}$.

PET images were reconstructed with (FORE) fourier rebinning and attenuation-weighted subset's expectation-maximization and all PET/CT images were displayed on a work station in axial, sagittal and coronal reformatted images, image analysis was done by two experienced radiologists in PET/CT analysis of at least 5 years of experience, the result was recorded and analyzed.

PET/CT image interpretation and reference stander: Qualitative evaluating of the pathologically proved primary mass/masses by measuring its dimensions, extension and nearby infiltration of surrounding organs the nearby lymph nodes for size, site and distant metastasis, quantitative analysis of the area of abnormal uptake was done followed by measuring of SUVmax by putting the Region of Interest (ROI) on primary and metastatic lesions at site of maximum uptake with taking the liver suVmax as a stander with its suVmax of 3 . Followed by calculations of $\Delta S U V_{\max }$ for both primary/primaries and metastatic lesions.

\section{Statistical analysis:}

All the PET and PET/CT finding of pulmonary and extrapulmonary results were recorded and analyzed using mean, standard deviation, minimum, median and maximum as quantitative data by using count (frequency) and relative frequency (percentages) for analyzing the data. Correlations between quantitative variables were done using Spearman correlation coefficient (Chan, 2003b). Sensitivity, specificity and accuracy with positive predictive values and negative predictive value were calculated, true positive considered when the result of PET or PET/CT were compatible with histopathology, and negative cases considered when result was not matched, $p$-values less than 0.05 were 
considered significant. The calculation was done by using a statistical software package (Medcalc version 18.116, Chicago, IL). suvmax and $\Delta$ SUV max were tabulated for both primary and metastatic lesions and by using the (ROC) curve with calculating area under the curve for determining the cutoff value between the primary and metastatic lesions.

\section{Standardized uptake value:}

SUV max defined as the maximum value of FDG uptake per pixel of tumour volume in the area of interest (VOI), SUV was normalized to patient weight and injected activity, suymax calculated for both primary and metastatic lesions in case of multiple metastases we chose the largest one, $\Delta$ SUV was measured as the difference between the suVmax of primary and secondary masses and expressed as a percentage (high $\mathrm{SUV}_{\max }{ }^{-}$ low $\mathrm{SUV}_{\max }$ )/high ${ }_{\text {suVmax }} \mathrm{X} 100$. We assessed the causes of false positive and false negative results of both PET and PET/CT.

\section{Results}

A total of 65 patients with multiple intra and extrapulmonary lesion (50 male and 15 female) their age ranged from 35 to 75 with mean age 53.25 years, patient's variables including smoking, site of primary lung cancer and metastatic lung cancer and degree of differentiation were tabulated in (Table 1) with no significant difference between the patient with primary lung cancer and those with metastatic lung lesions ( $p$-value 0.05).
The involved patient divided into two groups: The first group was metastatic group control) which included 47/65 (72.3\%). Patients with bronchogenic carcinoma and metastasis either in the lung or in different organs, the second group was synchronous second primary group included 18/56 (27.6\%), divided to $6 / 18$ with synchronous second primary cancer in distant organ and 12/18 with synchronous lung masses, the total number of lesions 160 masses. As shown in (Table 1).

Based on the histopathological data cases were; $47(72.3 \%)$ metastatic lung Cancer and 18 (27.6\%) second primary cancer with either synchronous in the lung or different sites at different organs.

Metastatic lung cancers (47) were found to be 34 non-small cell lung cancer NSCLC (72.3\%) and 13 small cell lung cancer SCLC (27.6\%) distributed as follow: 11 LUL (23.4\%), 5 RLL (10.6\%), 12 RUL (25.5 \%), 6 LLL (12.7\%), 3 LML (6.3\%), 5 RT hilum (10.6\%) and 5 LT hilum (10.6\%) the degree of differentiation were mainly of well and moderately differentiation.

Synchronous second primary lung cancers (18) were distributed as follow: 5 SCLC (27.7\%), 7 NSCLC (38.3\%), 1 case breast cancer (5.5\%), two cases of laryngeal cancer $(11.1 \%), 1$ case of liver cancer $(5.5 \%), 1$ case of renal cancer $(5.5 \%)$ and one case of colon cancer $(5.5 \%)$ while the degrees of differentiation were mainly of poor and undifferentiated as tabulated in (Table 1).

Table (1): Demographic data in both studied groups.

\begin{tabular}{|c|c|c|c|}
\hline \multirow{2}{*}{$\frac{\text { Patients variables }}{\text { Number }}$} & \multicolumn{2}{|c|}{ Metastatic lung cancers Second primary tumors } & \multirow[t]{2}{*}{$p$-value } \\
\hline & $47(72.3 \%)$ & $18(27.6 \%)$ & \\
\hline Age & $35-57$ (mean 52.25) & $25-72($ mean 53.7$)$ & 0.26 \\
\hline Sex & 6 female $(12.7 \%)$ & 7 female $(38.8 \%)$ & 0.41 \\
\hline Smoking & $25(55.3 \%)$ & $14(77.7 \%)$ & 0.001 \\
\hline Final diagnosis (histopathology) & $\begin{array}{l}\text { - } 34 \text { NSCLC }(72.3 \%) \\
\text { - } 13 \text { SCLC }(27.6 \%)\end{array}$ & $\begin{array}{l}\text { - } 7 \text { NSCLC }(38.8 \%) \\
\text { - } 5 \text { SCLC }(27.7 \%) \\
\text { - } 1 \text { invasive ductal carcinoma of breast }(5.5 \%) \\
\text { - } 1 \text { mucinous carcinoma of breast }(5.5 \%) \\
\text { - } 1 \text { renal cell carcinoma }(5.5 \%) \\
\text { - } 1 \text { hepatocellular carcinoma }(5.5 \%) \\
\text { - } 2 \text { laryngeal squamous cell carcinoma }(11.1 \%)\end{array}$ & \\
\hline \multicolumn{4}{|l|}{ Characteristic of primary: } \\
\hline Site & $\begin{array}{l}\text { 11 LUL }(23.4 \%) \\
5 \text { RLL }(10.6 \%) \\
\text { 12 RUL }(25.5 \%) \\
6 \text { LLL }(12.7 \%) \\
3 \text { LML }(6.3 \%) \\
5 \text { RT hilum }(10.6 \%) \\
5 \text { LT hilum }(10.6 \%)\end{array}$ & $\begin{array}{l}3 \text { LLL }(16.6 \%) \\
2 \text { RML }(11.1 \%) \\
3 \text { RUL }(16.6 \%) \\
4 \text { LUL }(22.2 \%) \\
1 \text { breast }(5.5 \%) \\
2 \text { laryngeal }(11.1 \%) \\
1 \text { liver }(5.5 \%) \\
1 \text { renal }(5.5 \%) \\
1 \text { colon }(5.5 \%)\end{array}$ & \\
\hline $\begin{array}{l}\text { Differentiation: } \\
\text { Well } \\
\text { Moderately } \\
\text { Poor } \\
\text { Very poor } \\
\text { Undifferntiated }\end{array}$ & $\begin{array}{l}-25(53.1 \%) \\
-12(25.5 \%) \\
-6(12.7 \%) \\
-3(6.3 \%) \\
-1(2.1 \%)\end{array}$ & $\begin{array}{l}-2(11.1 \%) \\
-2(11.1 \%) \\
-2(11.1 \%) \\
-8(44.4 \%) \\
-4(22.2 \%)\end{array}$ & 0.007 \\
\hline
\end{tabular}


The mean $\Delta \mathrm{SUV}_{\max }$ between the metastatic lung cancer (47 cases) was lower than the second primary lung disease (18 cases) at $25 \%-75 \%$ as seen in (Tables 2,3 ) with a $p$-value of (0.007). Although the ranges of the groups show $50 \%$ overlap, the majority $(75 \%)$ of patients with metastatic disease had a $\Delta \mathrm{SUV}_{\max }$ below $16.6 \%$ (median $20 \%$ ) as showed in Figs. (2,3), whereas the $\Delta \mathrm{SUV}_{\text {max }}$ exceeds $60.6 \%$ (median $68 \%$ ) for the majority of the second primary cancer as showed in Figs. $(6,7)$.
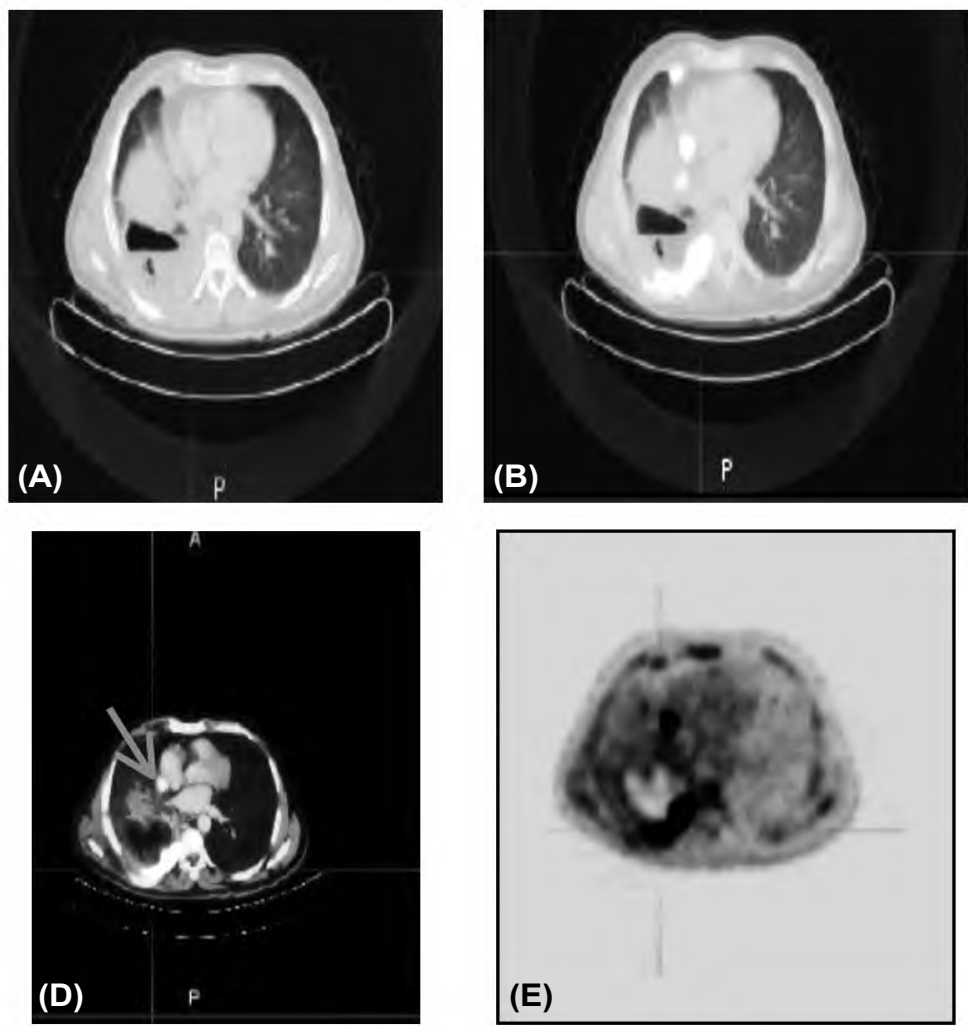

Table (2): $95 \%$ percentiles accuracy of $\Delta \mathrm{SUV}_{\max }$ in metastatic lung cancer.

\begin{tabular}{lll}
\hline Percentiles & & $95 \%$ confident level \\
\hline 25 & 50.0000 & 35.8471 to 57.7809 \\
75 & 68.7500 & 60.0000 to 80.0000 \\
\hline
\end{tabular}

Table (3): $95 \%$ percentiles accuracy in $\Delta \mathrm{SUV}_{\max }$ in second primary lung cancer.

\begin{tabular}{lll}
\hline Percentiles & & $95 \%$ confident level \\
\hline 25 & 8.0400 & 5.5000 to 11.1000 \\
75 & 20.0000 & 16.6440 to 25.0000 \\
90 & 26.8160 & 22.0032 to 47.8882 \\
\hline
\end{tabular}



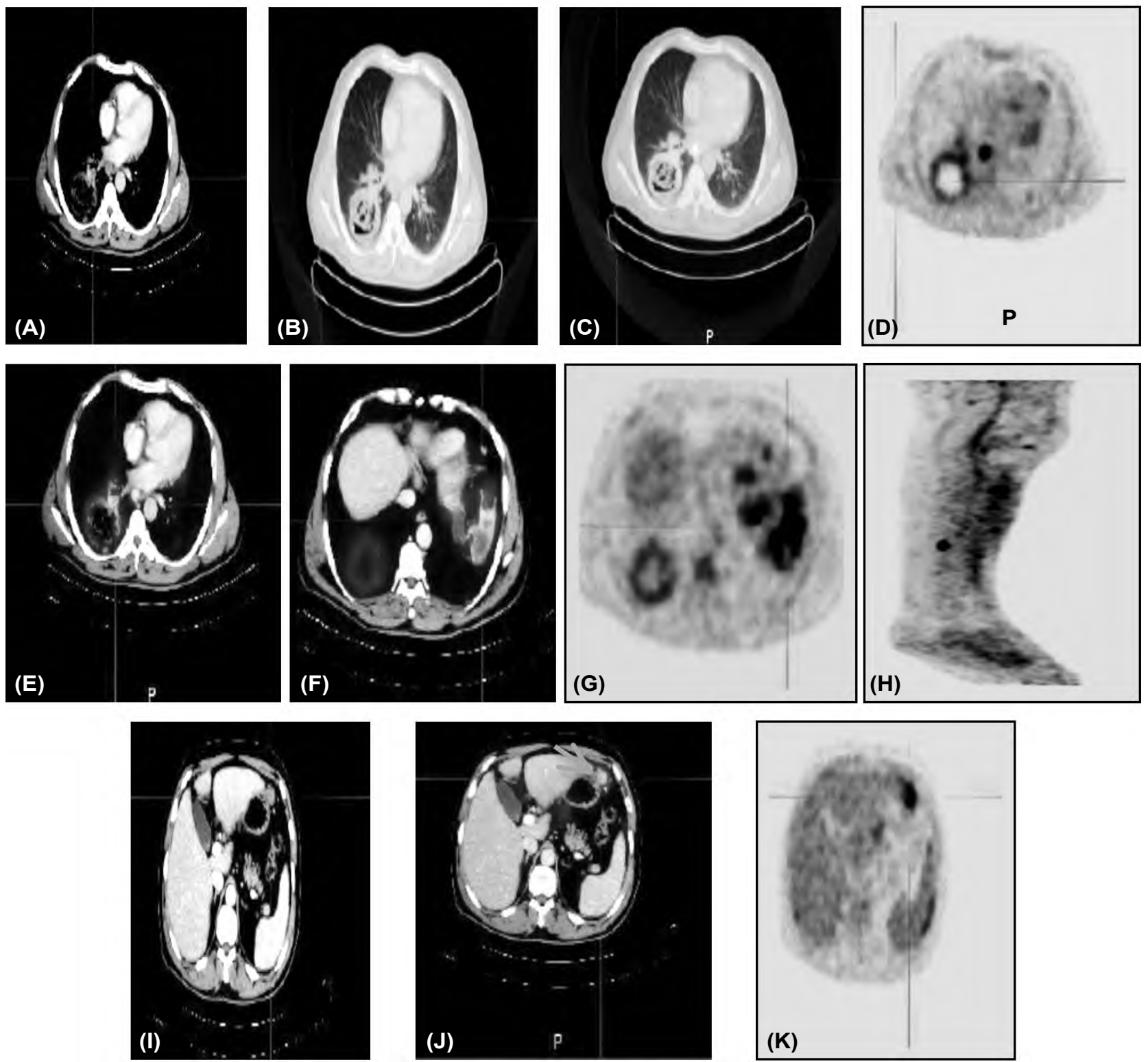

Fig. (3): A male patient aged 52 years complaining from dyspnea 3 months ago, CT chest with contrast was done and revealed right lower lobe cavitary lung lesion with air bronchogram (A \& D), he did PET (E), fused PET CT (B,C) which showed a welldefined cavitary mass in the apical segment of right lower lung lobe measuring $6.2 \mathrm{X} 7 \mathrm{~cm}$ with thick nodular wall and high metabolic activity of ${ }_{\text {SUVmax }} 7$, with multiple enlarged mediastinal lymph nodes the largest measured $3 X_{3} 3 \mathrm{~cm}$ with SUV max 11.5 (arrow), multiple metastatic lesion in form of peritoneal and omental deposits at outer aspect of stomach with SUV $\mathrm{Vax}_{\mathrm{max}}$ 8.8 (I, G, K), large sub phrenic collection with $12.4(\mathrm{H})$, multiple subcutaneous and intramuscular areas of metabolic activity in the thigh with suVmax 8.7 , histopathology confirm necrotic adenocarcinoma of the lung with metastatic deposits $\Delta$ SUVmax measured $20.45 \%$ consistent with metastatic.

Table (4): Sensitivity and specificity of the $\Delta$ SuVmax for both metastatic and secondary primary masses.

$\begin{array}{ll}\text { Area under the ROC curve (AUC) } & 0.848 \\ \text { Standard error a } & 0.0618 \\ \text { 95\% confidence interval b } & 0.740 \text { to } 0.924 \\ \text { Z statistic } & 5.634 \\ \text { Significance level } p \text { (area=0.5) } & <0.0001 \\ \text { Optimal criterion a } & >44.4 \\ \text { Sensitivity } & 81.82 \\ \text { Specificity } & 85.71\end{array}$

$p$-value $\Delta \mathrm{SUV}_{\max }$ were non-significant between different cases of metastatic lung lesions and different cases of secondary primary cases with $p$ value of 0.96 and 0.63 respectively while $p$-value was significant between metastatic and secondary primary $p$-value $<0.001$.

Sensitivity and specificity of the $\Delta \mathrm{SUV}_{\max }$ for both metastatic and secondary primary lesions were $81.8 \%$ and $85.71 \%$ as showed in (Table 4). 


\section{Area under the curves and cutoff values:}

This study measured area under the curve from (ROC) for both groups aiming to determine cutoff value. $p$-value $\Delta \mathrm{SUV}_{\max }$ were non-significant between different cases of metastatic lung lesions and different cases of secondary primary cases with $p$-value of 0.96 and 0.63 respectively while $p$-value was significant between metastatic and secondary primary $p$-value $<0.001$ as shown in (Table 5) and Fig. (4).

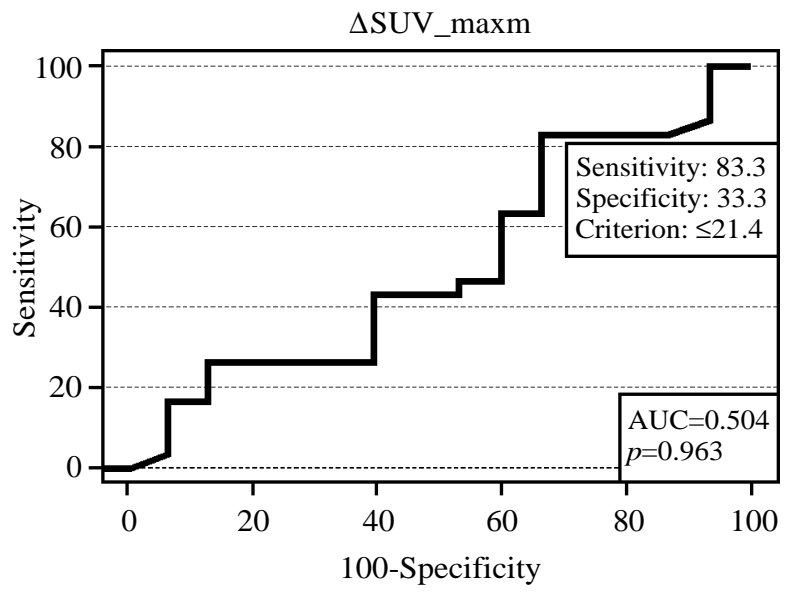

Table (5): Data of ROC for $\Delta \mathrm{SUV}_{\max }$ in both groups ( $\Delta \mathrm{SUV}$ -

\begin{tabular}{lcc}
\multicolumn{2}{c}{$\operatorname{maxm}$ and $\Delta S U V$-maxs $)$. } \\
\hline ROC data & $\begin{array}{c}\text { First group } \\
(\Delta S U V \text {-maxm }) \\
\text { metastatic }\end{array}$ & $\begin{array}{c}\text { Second group } \\
(\Delta \text { SUV-maxs }) \\
\text { synchronous second } \\
\text { primary lesions }\end{array}$ \\
\hline - Area under the ROC & 0.504 & 0.569 \\
- curve (AUC) & 0.0954 & 0.146 \\
- Standard error a & 95\% confidence interval b 0.351 to 0.657 & 0.319 to 0.795 \\
- Z statistic & 0.0466 & 0.471 \\
- Significant $p$ (area=0.5) & 0.9628 & 0.6377 \\
\hline
\end{tabular}

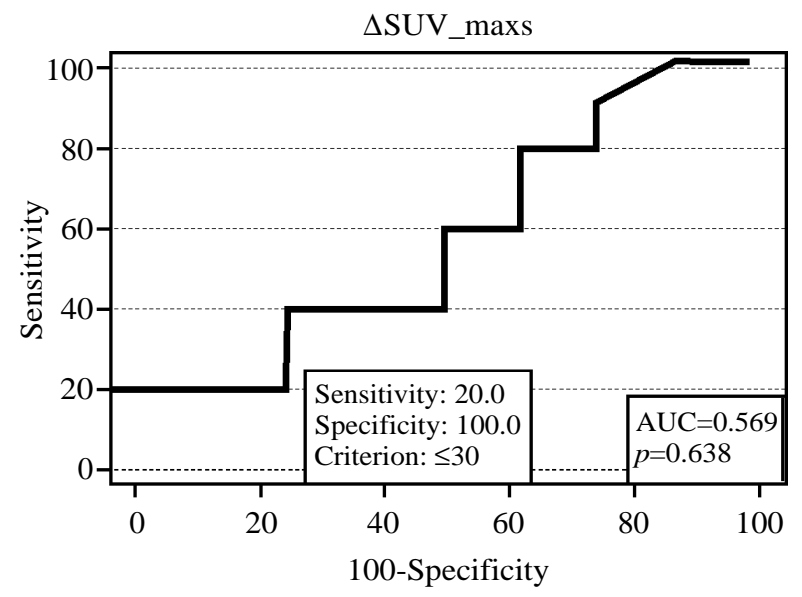

Fig. (4): ROC curve for metastatic lesions ( $\Delta$ SUV-maxm) and for synchronous second primary lesions $(\Delta S U V-m a x s)$.

The Area Under the Curve (AUC) for $\Delta \mathrm{SUV}_{\max }$ was for secondary primary lesions $\left(\Delta \mathrm{SUV}^{-}\right.$maxs $)$ 0.56 (95\%, CI: $0.31-0.79, p=0.63)$ and that for metastatic lesions ( $\Delta$ SUV-maxm) 0.50 (95\%, CI: 035-0.65, $p=0.96)$, while that of both $\left(\Delta \mathrm{SUV}_{\mathrm{max}^{-}}\right.$ both) was 0.94 (95\%, CI:0.85-0.98. $p<0.0001)$ Fig. (4), which represents a moderately high discriminating ability of the $\Delta S U V_{\max }$. The left upper corner of the ROC curve chosen as the optimal cutoff, which correspond to a $\triangle \mathrm{SUV}_{\text {max }}$ of $<35 \%$. This cutoff was associated with sensitivity and specificity of $93.3,91.1$ respectively as shown in (Table 6) and Fig. (5).

Table (6): ROC data for $\left(\Delta \mathrm{SUV}_{\max }\right.$-both) in both studied groups.

$\begin{array}{ll}\text { Area under the ROC curve (AUC) } & \\ \text { Standard error a } & 0.0344 \\ 95 \% \text { confidence interval b } & 0.859 \text { to } 0.987 \\ \text { Z statistic } & 12.994 \\ \text { Significance level } p(\text { area }=0.5) & <0.0001\end{array}$

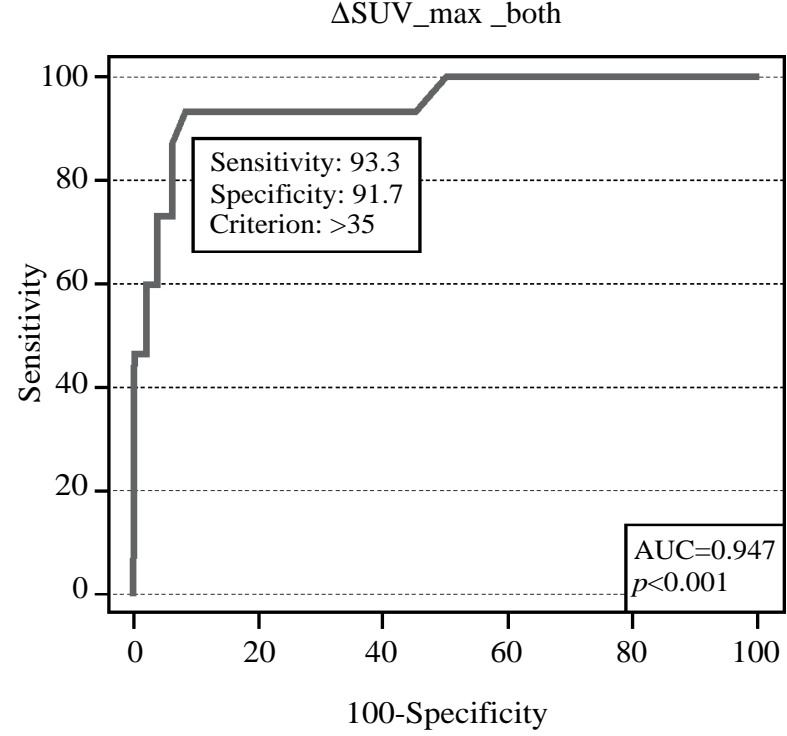

Fig. (5): ROC curve for $\Delta \mathrm{SUV}_{\max ^{-}}$both for both included study groups. 

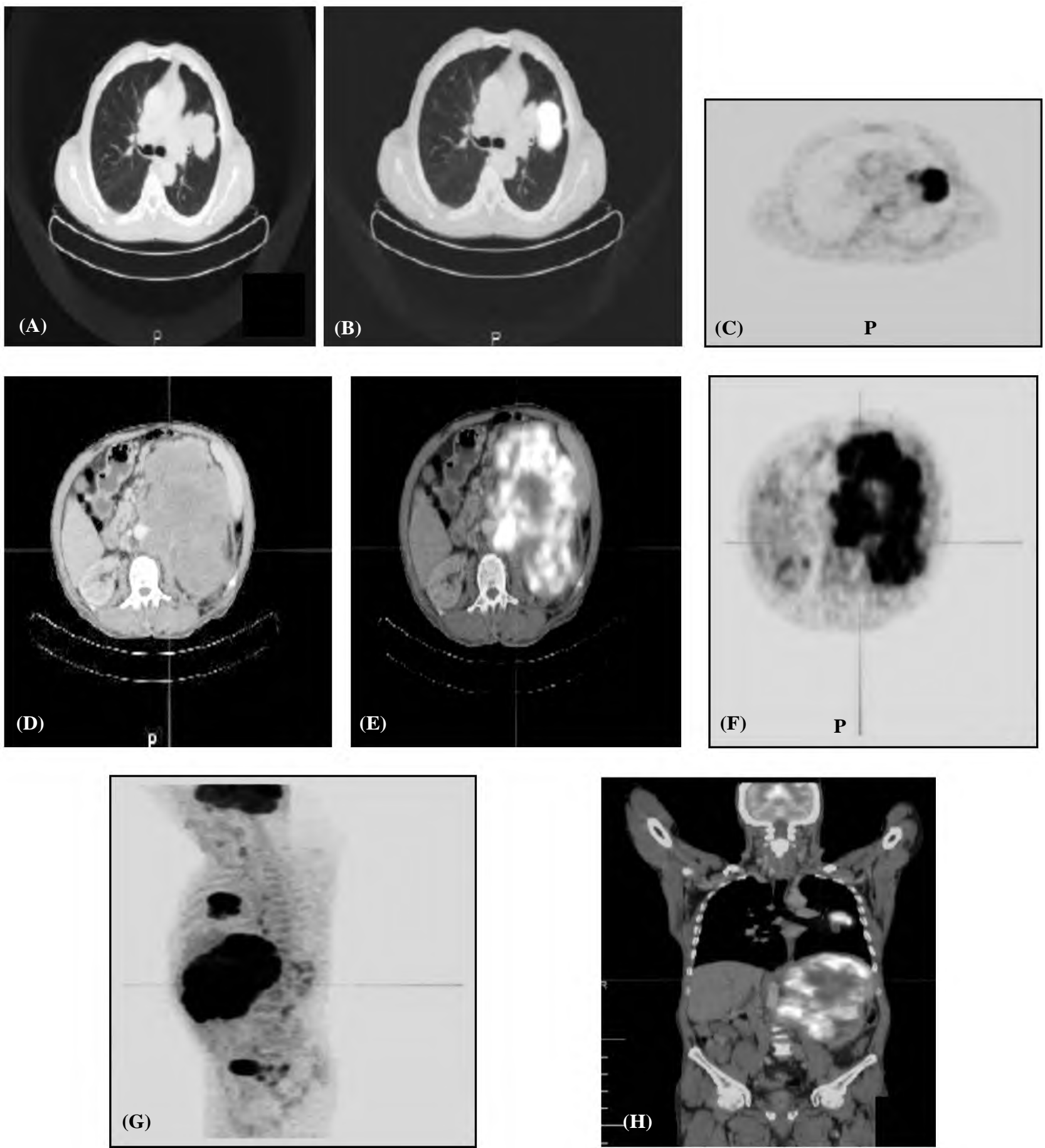

Fig. (6): A male patient aged 64 years old complaining of left loin pain for 6 months ago and did U/S which revealed large necrotic retroperitoneal soft tissue mass arising from the left kidney, (D, E, F) CT, fused PET CT and PET respectively showed a large necrotic metabolically active left retro-peritoneal soft tissue mass arising from the upper and middle pole of the left kidney and non-separable from left supra-renal gland, spleen and greater curvature of the stomach as well as the left psoas muscle with SuVmax 20.5. Another well-defined (A, B, C) speculated soft tissue mass seen at left upper lung lobe extending to lingual with central extension to mediastinum with suVmax 6.5 . Histopathological biopsy revealed the left retro-peritoneal mass as a necrotizing anaplastic adenocarcinoma while that of lung taken by bronchoscopic biopsy as adenocarcinoma of lung. $(\mathrm{G}, \mathrm{H})$ sagittal and coronal showed both masse, the $\Delta \mathrm{SUV}_{\max } 68.59 \%$ confirmed to be synchronous malignant primary pulmonary mass and malignant retroperitoneal mass at the same time. 
(A)

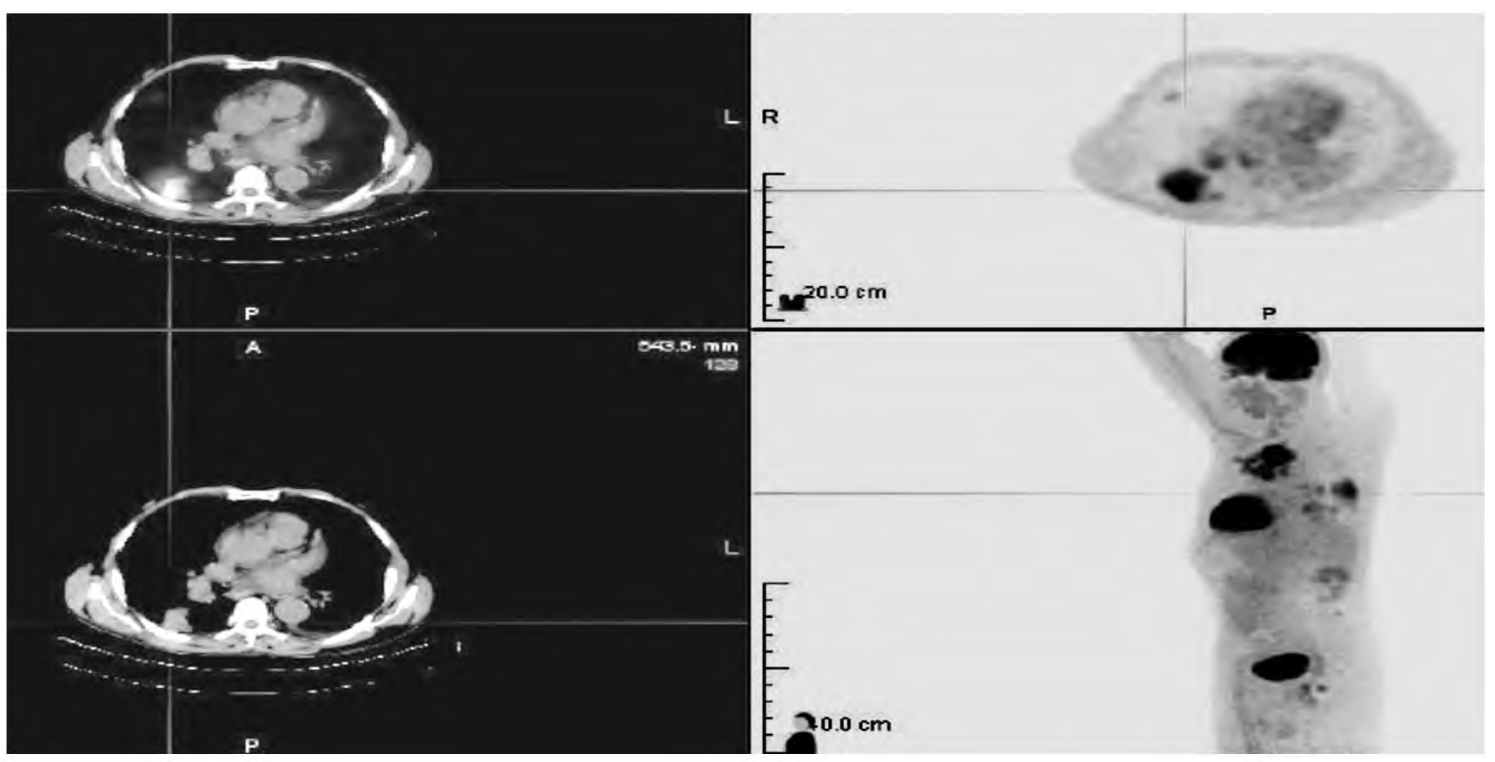

(B)

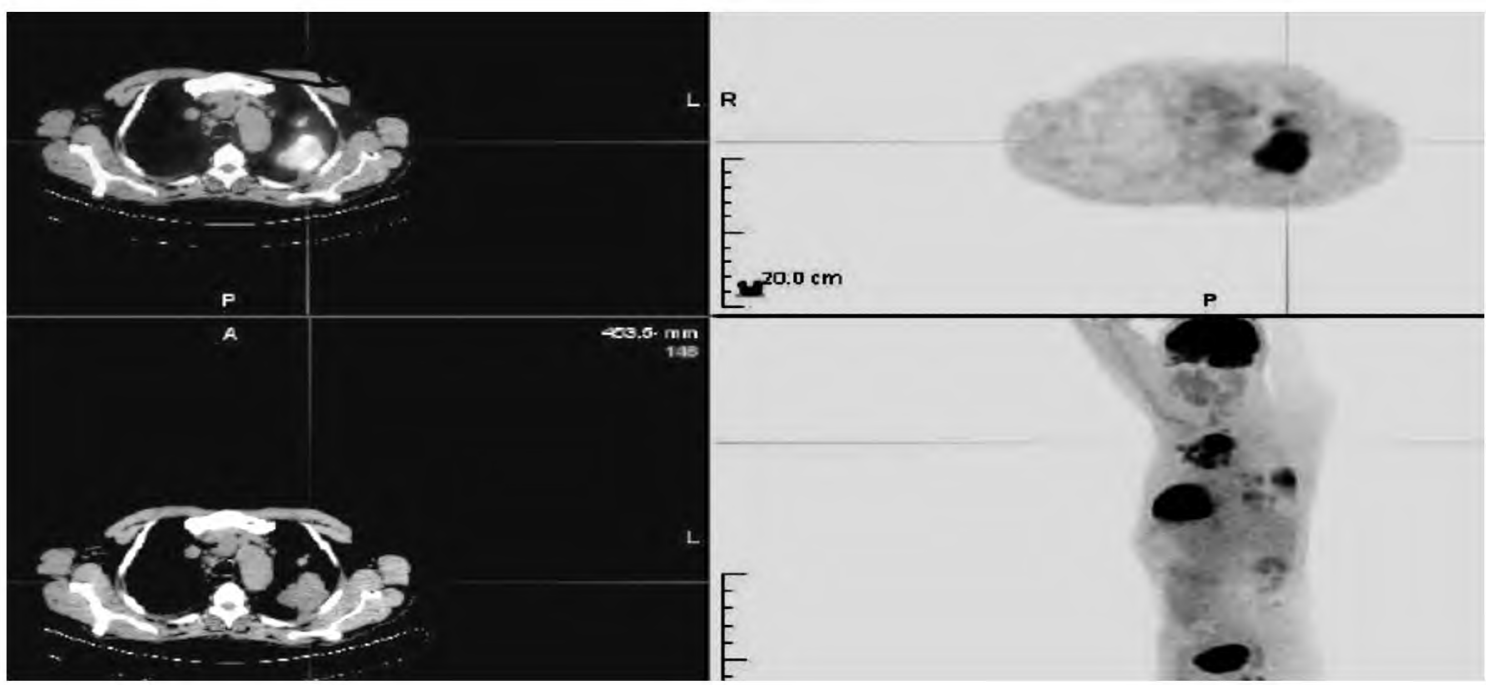

(C)

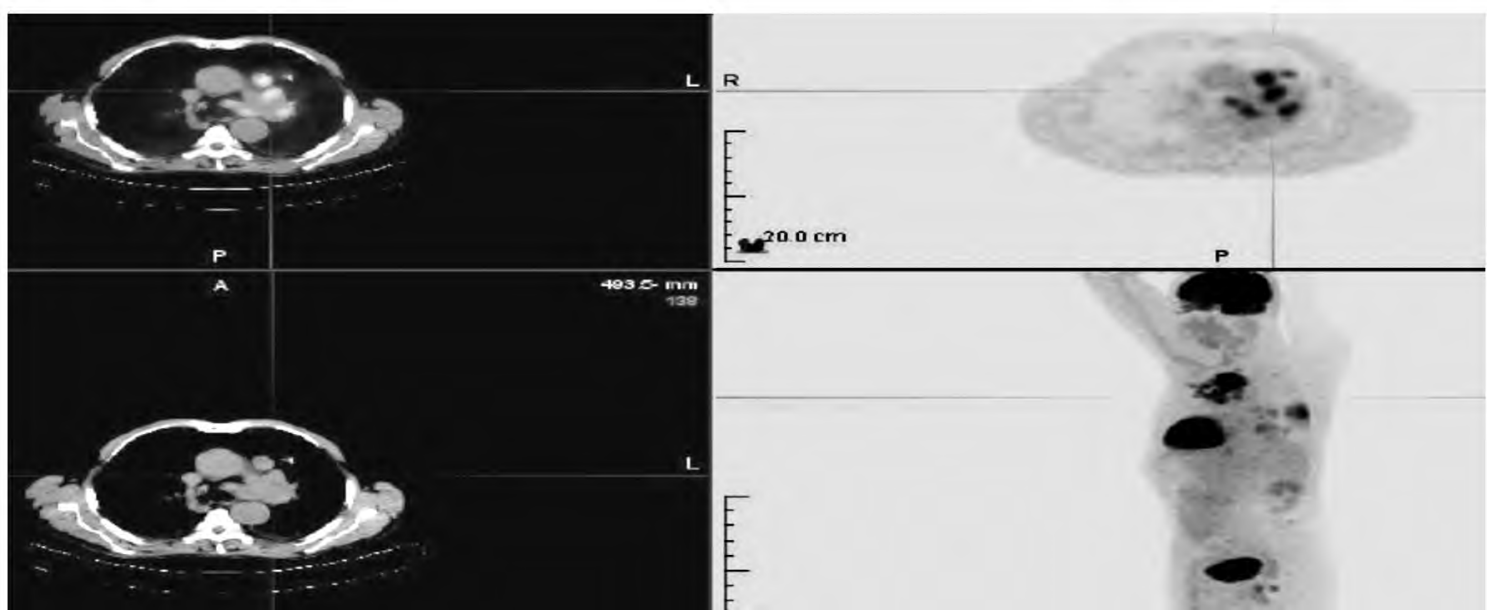

Fig. (7): A female patient aged 38 years old suffered from chest pain, loss of weight and dyspnea for 6 months ago. She did CT with contrast and revealed multiple pulmonary lesions and referred for PET CT unit for further assessment, (A, B) CT, PET, and fused PET CT showed two large irregulars speculated pulmonary soft tissue masses, one in the left apical segment of the lung with SUVmax $^{8}$ (A), another one in the right lower lung lobe with suVmax 18 (B) with multiple metabolically active pre-vascular and mediastinal lymph nodes (C). (D) The coronal image showed two metabolically active pulmonary masses. Histopathological biopsy revealed left one as adenocarcinoma and the right one as synchronous squamous cell carcinoma with $\Delta \mathrm{SUV}_{\max } 55.5 \%$. 


\section{Discussion}

Multiple pulmonary and extrapulmonary masses are a common problem we faced in oncology work and when we see two or more lesions in the lung or any different organ, we considered it as metastasis for the first possibility, nowadays incidence of synchronous primary tumours exploding because of a revolution in imaging modalities and advanced cancer therapy and prolonged survival rate of the cancer patient, synchronous primary tumour defined as the tumour occurred at the same time or within 6 months of the occurrence of the first primary tumour and discovered during the period of chemo or radiotherapy or on follow-up.

Little previous studies and case reports tried to explain the coexistence of two primaries detected by FDG and involving mainly the lung due to immunologic or genetic defects, prolonged exposure to carcinogens, radiation and chemotherapy for primary cancer, and field cancerization [10-14].

Few previous types of researches study the role of PET CT in differentiating between multiple lesions as synchronous primary or metastatic [9].

Our study included 65 cases, most of them were metastatic with no significant sex or age predominance. There was significant correlation between the smoking and incidence of pulmonary and extrapulmonary lesions with a $p$-value of 0.001 , this matched with the result of Furrukh M. [15], who accused smoking as a causative factor for lung cancer in developing countries.

$58,4 \%$ of our studied cases were pathologically proved as Non-Small Cell Lung Cancer (NSCLC), this result was consistent with the result of W.D. Travis [16], who considered NSCLC as the most frequent type of lung cancer.

In our study we found that the most common lobe affected were the upper lung lobe $(61.1 \%)$ and this was the same result of Jamnik et al. [17] who stated that the upper lobes most commonly affected by the malignant process may be due to accumulation of toxin and carcinogens for long period due to lack of proper ventilation and lymphatic drainage as a result of less efficient delivery of protective materials through the circulation to upper lobes when compared to lower lobes, this occurs due to ventilation/perfusion ratio was greater in upper lobes than lower lobes especially in the smoker.

We found also in this study that the most of the lung metastatic masses were of a well and moder- ately differentiation (37/47) while that of the second primary tumour was of very poor and undifferentiated $(12 / 18)$ with significant $p$-value 0.007 this due to the similarity in the cell of origin between the primary and metastasis unlike second primary tumours, where they were totally different in the type of cells and this consistent with Barletta JA et al. [18].

In 65 studied cases, most of them were metastasis and showed lower $\Delta \mathrm{SUV}_{\max }$ than in the second primary group with moderately accuracy $(0.94)$ as detected by AUC and higher sensitivity $(81.8 \%)$ and specificity $(85.7 \%)$ this indicate the high ability of $\Delta \mathrm{SUV}_{\max }$ in discrimination between the metastatic lesions and synchronous primary lesions.

Some researches (Dijkman et al.) [19] were matched with our result as the found $\Delta \mathrm{SUV}_{\max }$ was lower in metastatic than secondary primary lesions with both sensitivity and specificity $81 \%$ and determine cutoff value of $41 \%$.

Huynh Quang Huy [9] who studied 81 patients with non-small cell lung cancer (44 metastatic and 37 second primary cancer) retrospectively and he evaluated suvmax in both groups and found that the suVmax was significantly higher in patients with a second primary tumour with $p$-value $<0.001$ that were matched with our results.

Nobuyuki Kosaka et al. [20], who studied the role of SUV value differences between primary and metastatic lesions of patients with lung cancer and concluded that the SUVs of most metastatic lesions ranged from half to double those of primaries in lung cancer patients. When the SUV of a suspected metastasis was not in this range, other non-metastatic lesions should be considered. This highly matched with our results of higher SUV values in second primary tumours group.

Few studies supported our result about the ability of PET CT in differentiating between the metastatic group where they had the same origin and biological behaviour and those of separate origin (multiple primaries), FDG uptake by the lesion had been reported to be related to several tumour characteristics including the histological type and aggressiveness of the tumour [21-23].

Several limitations faced our study, firs it was a retrospective study. We collected cases which already had taken a biopsy and confirmed histopathological diagnosis, if another study supports our hypothesis and cutoff value and depended upon it in diagnosis before biopsy, it may determine the actual nature of multiple lesions and determine the 
most suitable one for biopsy according to $\mathrm{SUV}_{\max }$, and this will help in the improvement of diagnosis and management.

The second limitation was in case of multiple pulmonary lesions the biopsy was taken from the largest mass, which might be not the one matched with actual FDG PET activity result (not the largest one is the target) and patient considered falsely metastatic rather than considering second primary lung cancer.

The third limitation was once primary diagnosed, the other lesions considered metastatic and the diagnosis and management had been taken without any further assessment. This urging of rising awareness of physician about the increasing possibilities of synchronous second primary tumour should be raised.

\section{Conclusion:}

As the PET CT considered as functional noninvasive technique, we recommended it for all patients with multiple pulmonary and extrapulmonary lesions to improve diagnostic accuracy before taken the decision of management as it could differentiate between the multiple primaries and metastatic lesion depending upon the FDG activity. We recommend further prospective studies by doing PET CT firstly and chosen the lesions to be biopsied and compared the result with histopathology, this will improve the diagnosis and strategy of treatment.

\section{Declarations:}

1- Ethics approval and consent to participate: Informed consents taken from the patients and the study approved by Ethical Committee of Faculty of Medicine and University Hospital 2019-145.

2- Consent for publication: Authors accepted to publish the paper.

3- Availability of data and material: The author's confirm that all data supporting the finding of the study are available within the article and the raw data ad data supporting the findings were generated and available at the corresponding author on request.

4- Funding: No funding. Not applicable for this section.

5- Acknowledgements: To all the staff members and workers of Radiology and Oncology Departments of Tanta University Hospitals.

\section{References}

1- RIDGE A.C., MCERLEAN M.A. and GINSBERG M.S.: Epidomiology of lung cancer: Semin intervent Radiol., 30: 93-8. https://doi.org/10.1055/s-0033-1342949, 2013.

2- BRAY F.: Global cancer statistics: GLOBOCAN estimates of incidence and mortality worldwide for 36 cancers in 185 countries. 2018 CA Cancer J. Clin.. DOI: 10.3322/ caac.21492, 2018.

3- VAN RENS M.T., ZANEN P., BRUTEL DE LA RIVIÈR A., et al.: Survival in synchronous VA. Single lung cancer: Upstaging better reflect prognosis. Chest, 118: 952-8. https://doi.org/10.1378/chest.118.4.952, 2000.

4- CHENG SHEN, XIN WANG, LONG TIAN, et al.: "Different trend" in multiple primary lung cancer and intra pulmonary. European Journal of Medical Research, 5: 20-17. https://doi.org/10.1186/s40001-015-0109-5, 2015.

5- MOUNIR S.G., MOHAMED G., OSMAN A.M., et al.: Role of PET/CT in Differentiating bronchogenic Carcinoma from Inseparable Pseudo-Neoplastic Lesions. The Egyptian Journal of Hospital Medicine, 72 (4): 4264-9. https://dx.doi.org/10.12816/eihm.2018.9238. 2018.

6- CHANG Y.L., WU C.T. and LEE Y.C.: Surgical treatment of synchronous multiple primary lung cancers: Experience of 92 patients. J. Thorac Cardiovasc. Surg., 134: 630-7. https://doi.org/10.1016/i.jtcvs.2007.06.001, 2007.

7- KHALIL A., MAJLATH M., GOUNANT V., et al.: Contribution of magnetic resonance imaging in lung cancer imaging; Diagnostic and Interventional Imaging, 97: 9911002. http://dx.doi.org/10.1016/j.diii.2016.08.015, 2016.

8- De GUEVARA HERNÁNDEZ D.L.: The Role of PET/CT Imaging in Lung Cancer. Journal of Cancer Therapy, 6: 690-700. https://doi.org/10.4236/jct.2015.68076, 2015.

9- HUYNH QUANG HUY: Comparison of the $\mathrm{SUV}_{\max }$ between lung metastasis and synchronous second primary lung tumors in patients with non-small cell lung cancer biomedical research, 29: 21. https://doi.org/10.4066/ biomedicalresearch. 29-18-1134, 2018.

10- MITTRA E., VASANAWALA M., NIEDERKOHR R., et al.: A case of three synchronous primary tumors demonstrated by F-18 FDG PET. Clin. Nucl. Med., 32: 6667. https://doi.org/10.1097/rlu.0b013e3180a1ad48, 2007.

11- VAN WESTREENEN H.L., WESTERTERP M., JAGER P.L., et al.: Synchronous primary neoplasms detected on 18F-FDG PET in staging of patients with esophageal cancer. J. Nucl. Med., 46: 1321-5, 2005.

12- ADRIAENSEN M., SCHIJF L., DE HAAS M., et al.: Six synchronous primary neoplasms detected by FDG-PET/ CT. Eur. J. Nucl. Med. Mol. Imaging, 35: 1931. https:// doi.org/10.1007/s00259-008-0821-2, 2008.

13- OBANDO J.A., SAMII J.M. and YASREBI M.: A case of two synchronous primary lung tumors demonstrated by FDG positron emission tomography. Clin. Nucl. Med., 33: 775-7. https://doi.org/10.1097/rlu.0b013e 318187ef85, 2008.

14- JEON S.Y., AHN S.H., KIM C.H., et al.: Esophageal and laryngeal cancer incidentally found on $[18 \mathrm{~F}]$ fluorodeoxyglucose positron emission tomography/computed tomography during the staging workup for lung cancer. Clin. 
Lung Cancer, 9: 230-1. https://doi.org/10.3816/ clc.2008. n.035, 2008.

15- FURRUKH M.: Tobacco Smoking and Lung Cancer: Perception-changing facts. Sultan Qaboos University Medical Journal, 13 (3): 345-58. https://doi.org/ $10.12816 / 0003255,2013$

16- TRAVIS D., BRAMBILLA E., MÜLLER-HERMELINK H.K., et al.: The 2015 World Health Organization Classification of Lung Tumors: Impact of Genetic, Clinical and Radiologic Advances Since the 2004 Classification, J. Thorac Oncol. Sep., 10 (9): 1243-60. doi: 10.1097/ JTO.0000000000000630, 2015.

17- JAMNIK S., UEHARA C. and D. SILVA V.V.: Location of lung carcinoma in relation to the smoking habit and gender. J. Bras. Pneumol., 32 (6): 510-14. doi: 10.1590/ s1806-37132006000600007, 2006.

18- BARLETTA J.A., YEAP B.Y., CHIRIEAC L.R., et al.: Prognostic significance of grading in lung adenocarcinoma. Cancer, 116 (3): 659-69. doi: 10.1002/cncr. 2483110.1002/ cncr. 24831, 2010.

19- DIJKMAN B.G., SCHUURBIERS O.C.J., VRIENS D., et al.: The role of 18 F-FDG PET in the differentiation between lung metastases and synchronous second primary lung tumors. Eur. J. Nucl. Med. Mol. Imaging, 37: 2037 47. https://doi.org/10.1007/s00259-010-1505-2, 2010.

20- NOBUYUKI K., TATSURO T., KAZUNOBU T., et al.: Standardized uptake value differences between primary and metastatic lesions in 18F-FDG PET/CT of patients with lung cancer. Acta Radiologica, Vol. 56 (11): 132935. DOI: 10.1177/0284185114556705, 2015.

21- De GEUS-OEI L.F., VAN DER HEIJDEN H.F., CORSTENS F.H., et al.: Predictive and prognostic value of FDG-PET in non-small cell lung cancer: A systematic review. Cancer, 110: 1654-64. https://doi.org/10.1002/cncr. 22979, 2007.

22- VESSELLE H., SALSKOV A., TURCOTTE E., et al.: Relationship between non-small cell lung cancer FDG uptake at PET, tumor histology, and Ki-67 proliferation index. J. Thorac. Oncol., 3: 971-8. https://doi.org/ 10.1097/ jto.0b013e31818307a7, 2008.

23- HIGASHI K., UEDA Y., AYABE K., et al.: FDG PET in the evaluation of the aggressiveness of pulmonary adenocarcinoma: Correlation with histopathological features. Nucl. Med. Commun., 21: 707-14. https://doi.org/ 10.1097/ 00006231-200008000-00002, 2000.

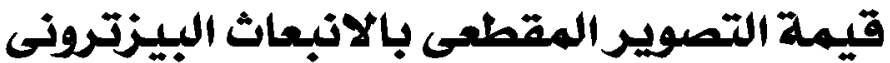

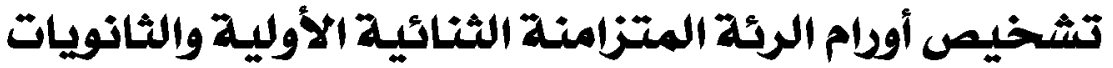

\author{
المقدمة: في حالة تعدد الأورام داخل وخارج الرئة، من الصعب تصديد ما إذا كانت الرئة هي المكان الأول أو ثانويات خبيثة من مكان بعيد، \\ حتى من الصعب تحديد أين الأودام الأولية.
}

الهدف من العمل: يمكننا قياس قيمة الامتماص الموحدة الفظمى فى الثانوى والثانويات المنتشرة فى حالة تعدد الأودام الرئوية وتحديد

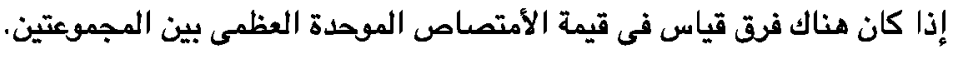

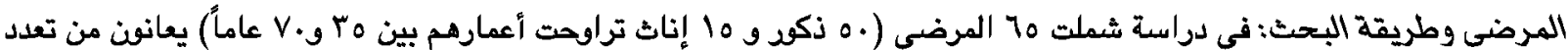

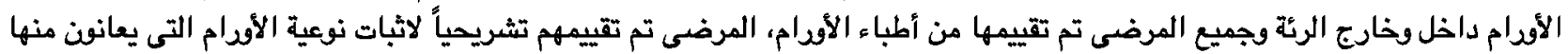

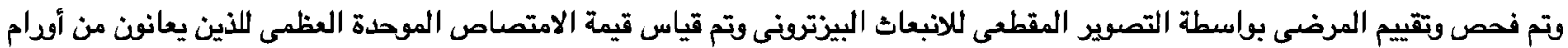

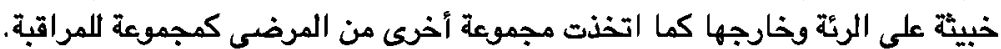

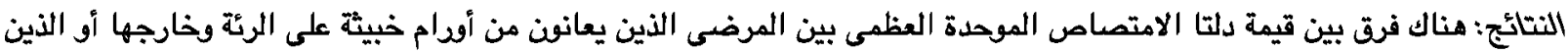

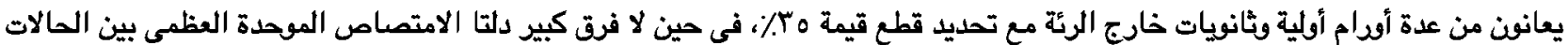

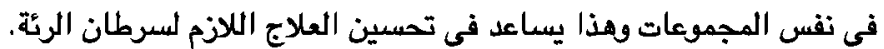

الخلاصة: تعتبر إضافة التصوير بالاشعة المقطعية بالانبعاث البيزترونى تقنية جديدة قد تساهم فى زيادة القدرة على التشخيص والقدرة

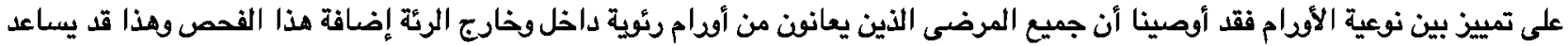
على تشخيص وعلاج أفضل لالأودام. 